\title{
Justification of the parameters of a pneumatic conveyor for active ventilation of soybean during storage
}

\author{
Sholpan Duisenova ${ }^{1}$, Aibek Atykhanov ${ }^{2}$, and Dimitar Karaivanov ${ }^{3, *}$ \\ ${ }^{1}$ Department of Agricultural Machinery and Technology, Faculty of Engineering, KazakhNational Agrarian University, 8 Abay Ave., \\ 050010 Almaty, Kazakhstan \\ ${ }^{2}$ Department ofAgricultural Machinery and Technology, Faculty of Engineering, Kazakh National Agrarian University, 8 Abay Ave., \\ 050010 Almaty, Kazakhstan \\ ${ }^{3}$ Department of Applied Mechanics, Faculty of Metallurgy and Material Sciences, University of Chemical Technology and \\ Metallurgy,8 Kliment Ohridski Blvd., 1756 Sofia, Bulgaria
}

\begin{abstract}
The article proposes a methodology for studying the productivity (capacity) and power consumption of a pneumatic conveyor for active ventilation of soybeans in container-modular storage in farms and the factors affecting them. In determining the parameters of the pneumatic conveyor, the physical and technological characteristics of the grain (soybean) are taken into account. The proposed methodology is based on the method of classical calculation for selecting a pneumatic conveyor with nominal parameters, which is necessary not only for transportation, both vertically and horizontally, but also for active ventilation of grain in containers during storage. The purpose of the methodology is to select a specific pneumatic conveyor for container-modular equipment for soybeans storage in the conditions of farms in Kazakhstan.
\end{abstract}

\section{Introduction}

Soybean storage can be short-term (temporary) and long-term. The first one is calculated in days or months (one to three) in duration, while the second one lasts from several months to several years. Both short-term and long-term storage should be organized in a way that there are no losses in weight (except for unavoidable ones) and, even more so, losses in quality.

In practice, two ways of storing grain are used: in tare (in bags) and in bulk (in stores, hoppers, silos).

Storage in tare is used only for some batches of seed: elite seeds, beans, seeds containing essential oils, small-grain seeds, corn seeds, beets, sunflower. This method of storage is more expensive, but it must be used in certain cases to prevent the loss of grain and seed in mass and quality [1].

The main method of soybean storing is storage in bulk [1]. This storage method has such disadvantages as the absence of air flow through the entire volume of the grain mass, as a result of which "dead zones" are formed which are devoid of airflow, leading to clumping and moistening of the grain, which leads to significant grain losses. In addition, rodents and birds eating grain also increase losses.

In [2] a modular equipment for grain storage with active ventilation, eliminating these drawbacks, is proposed. The main idea of this work is that standard containers for the transportation of goods with a capacity of 10-80 cubic meters are used as containers for grain (soybean) storage. Each module consists of a selected container, pneumatic conveying aggregate, pipelines, and control and monitoring instruments.
Equipment for grain storage with active ventilation, includes a hopper for grain storing, characterized in that the hopper is made in the form of a vertically situated container, while its lower part (bottom) is made conical at an angle of at least $40^{\circ}$ with a lower hole connected to the pneumatic conveyor through a nozzle and on the inner side, on three equidistant levels along the height of the container, are placed humidity sensors, which are fixed on the steel pipes, and a sensor control and monitoring panel is installed on the outer side of the container.

In Fig. 1 a sketch of the equipment is presented.

The main component of the equipment is a pneumatic conveyor consisting of a conveying aggregate (a blower and a supply cyclone (multicyclone) with filter), pipelines, and cyclones-unloaders, designed for suck-blow vertical or horizontal conveying of soybean or any other cereal crop over considerable distances [3].

The equipment for grain storage with active ventilation performs three cycles: loading, venting and unloading and operates as follows:

Loading of grain (Fig.1) into an equipped container 2 from a vehicle 3 is carried out by a pneumatic conveying aggregate 1 through a loading pipeline 9 , then through a vertical pipeline 7 into a cyclone 5 , where the air-grain flow is separated into air, which is removed through a nozzle 15, and into grain, which is settled down in container 2 for storage. The gate valve in the lower part of the cyclone 5 is driven by an electric motor.

Active ventilation of grain in container 2 is carried out in a closed circle with the pneumatic conveying aggregate 1 from the lower nozzle (with rotary valve) 12 of the container through a two-way valve 14, then

*Corresponding author: dipekabg@yahoo.com 
through the vertical pipeline 7 , the cyclone 5, and returns to the storage container 2 .

Unloading of grain from the storage container is made from its lower nozzle by the pneumatic conveying aggregate 1 , through the two-way valve 14 , a pipeline 8 through a cyclone 6 into a vehicle 3 [2].

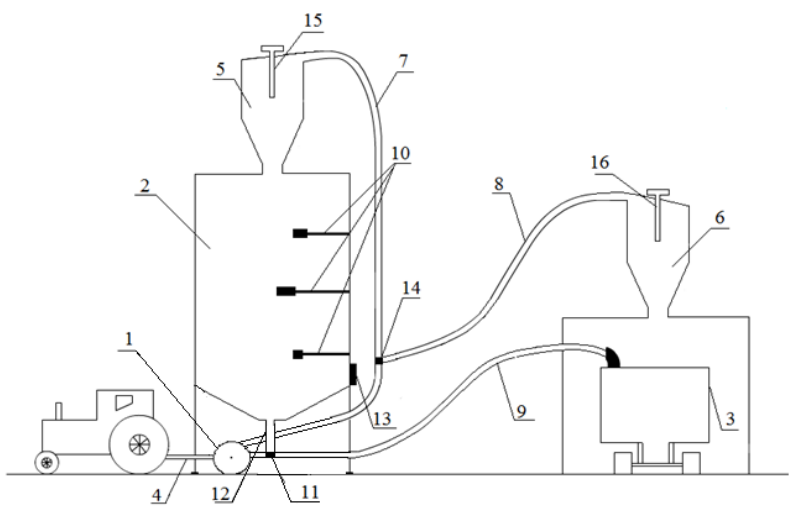

Fig. 1. Equipment for grain storage with active ventilation [2]: 1 - pneumatic conveying aggregate; 2 - container; 3 - vehicle from where the grain is loaded and where it is unloaded; $4-$ mechanical transmission for the conveyor driving (if any); 5 and 6 - grain separating (discharging) cyclones-unloaders; 7 pipeline for active ventilating or loading; 8 - pipeline for unloading; 9 - pipeline (hose) for loading of grain mass; 10 humidity sensors; 11 - two-way valve; 12 - lower nozzle; 13 Sensor control and monitoring panel; 14 - two-way valve; 15 and 16 - nozzles (with filters) for removal of air flow from the cyclones.

The aim of this article is to propose a methodology for studying and justifying the parameters and operating modes of the pneumatic conveyor, taking into account the physical characteristics of the material, during storage and active ventilation of soybeans by the proposed technology and determining its optimal parameters.

\section{Calculation of the equipment}

For the calculation of the pneumatic conveyor, the given in [4] method (calculation method of the suction equipment) is assumed. This is a classical method of selecting a pneumatic conveyor with nominal parameters, which is necessary not only for transportation, but also for active ventilation of grain in storage containers.

\subsection{Flow rate calculation}

Calculations are based on equipment with a 40-ton container and where all material (soybeans) in it should be shifted for 10 hours. So, a specified (real) mass flow rate (capacity, productivity) of the pneumatic conveyor is adopted as $G_{s p}=4 \mathrm{t} / \mathrm{h}$. The estimated (ideal) mass flow rate $G$ is determined as follows [5]:

$$
G=K_{s a f} \cdot G_{s p}
$$

where
$G_{s p}$ - specified mass flow rate;

$K_{\text {saf }}$ - safety factor $\left(K_{\text {saf }},=1.2\right.$ for grain and $K_{\text {saf }}=1.15$ for intermediate products).

\subsection{Pipeline calculation}

The estimated air velocity $v(\mathrm{~m} / \mathrm{s})$ in the pipeline is determined by the following formula [5]:

$$
v=k\left(10.5+0.57 v_{s p e}\right)
$$

where

$v_{s p e}$ - velocity of the material particles (for soybean $v_{s p e}=$ $15), \mathrm{m} / \mathrm{s}$;

$k$ - coefficient of sustainable conveying, depending on the material properties (for grain $k=1.2 \div 1.5$ ).

The estimated air velocity in the pipelines of the interdepartmental pneumatic conveying systems is taken according to a solids loading ratio (particle mass loading $=$ mass flow rate of particles/mass flow rate of air) $\mu$ of the air-grain flow as follows:

$v=20 \mathrm{~m} / \mathrm{s}$ for $\mu$ up to $0.5 \mathrm{~kg} / \mathrm{kg}$;

$v=22 \mathrm{~m} / \mathrm{s}$ for $\mu$ more than $0.5 \mathrm{~kg} / \mathrm{kg}$;

The value of $\mu$ for interdepartmental pneumatic conveying systems is assumed up to $3.5 \mathrm{~kg} / \mathrm{kg}$ (for bran, animal feed, and flour) and $3.5 \div 5 \mathrm{~kg} / \mathrm{kg}$ for grain [5, 6]. For soybean, the more appropriate value is $\mu=3.6$ $\mathrm{kg} / \mathrm{kg}$. Also, the solids loading ratio (particle mass loading) of the air-grain flow can be determined by the following formula:

$$
\mu^{\prime}=\frac{1000 G}{\rho_{r e c} \cdot Q_{e p}^{\prime}},
$$

where

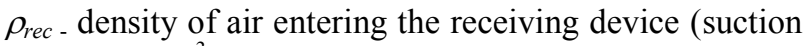
nozzle), $\mathrm{kg} / \mathrm{m}^{3}$;

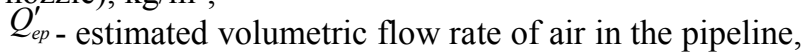
$\mathrm{m}^{3} / \mathrm{h}$;

$G$ - conveyor mass flow rate, $\mathrm{t} / \mathrm{h}$.

Since the atmospheric air (whit $\rho_{a}$ ) is used, under normal atmospheric (free air) conditions the air density is $\rho_{\text {rec }}=$ $\rho_{a}=1.2 \mathrm{~kg} / \mathrm{m}^{3}$.

The estimated volumetric flow rate in the pipeline is determined from formula (3) as follows:

$$
Q_{e p}^{\prime}=\frac{1000 G}{\rho_{\text {rec }} \cdot \mu} .
$$

Theoretically required diameter of a circular pipeline bore is calculated by the following formula [7]:

$$
D^{\prime}=\sqrt{\frac{4 Q_{e p}^{\prime}}{3600 \pi \cdot v}}
$$

The diameter of pipeline bore is rounded to the nearest larger or smaller value $D$, according to the 
current GOST for pipes and determine the cross-section area of the pipeline given by

$$
F=\frac{\pi \cdot D^{2}}{4} .
$$

Then the volumetric flow rate of air in the pipeline is

$$
Q_{e p}=3600 F \cdot v
$$

From the operating work of such equipment, it follows that when choosing the diameter of the pipeline it is necessary to observe a ratio of 100 to 1 , that is, at $10 \mathrm{~m}$ of the pipeline height, the diameter should be equal to $0.1 \mathrm{~m}$. Accordingly, in our case the diameter of the pipeline should be within $80-145 \mathrm{~mm}$.

However, the validity of these calculations must be verified empirically, which is supposed to be done in our further studies.

\subsection{Pressure drop calculation}

The pressure drop (loss) in the pneumatic conveyor $H_{p t}$ is determined by the following formula [8]:

$$
\begin{aligned}
H_{p t} & =H_{c a r s}+H_{r e c}+\sum H_{0}+\sum H_{f r . v}+\sum H_{f r . h}+ \\
& +\sum H_{t a p}+H_{v . c}+H_{c . u}
\end{aligned}
$$

where

$H_{\text {cars }}$ - pressure drop in the blower and in the gravity flow pipe (lower nozzle);

$H_{\text {rec }}$ - pressure drop in the receiver;

$\sum H_{o}$ - the amount of pressure drop to accelerate velocity of fed into a pipeline material to it conveying velocity (acceleration of the material) and to retrieve (redress) the air-grain flow velocity after bends;

$\sum H_{f r . v .}, \sum H_{f r . h}$ - the amount of pressure drop of friction during the movement of the air-grain flow in straight vertical and horizontal sections of the pipelines;

$\sum H_{b}$ - the amount of pressure drop in bends;

$H_{v . c}$ - pressure drop during the vertical conveying;

$H_{c . u}$ - pressure drop in a cyclone-unloader;

1) Since the value of the pressure drop $P_{\text {cars }}$ is small, it can be taken $H_{\text {cars }}=150 \mathrm{~Pa}$.

2) The pressure drop (loss) in the receiver is determined by the following formula:

$$
H_{r e c}=\xi_{r e c} \cdot \rho_{r e c} \frac{v_{r e c}^{2}}{2},
$$

where

$\xi_{\text {rec }}$ - loss factor, depended on the type of receiver;

$\rho_{\text {rec }}=\rho_{a}=1.2 \mathrm{~kg} / \mathrm{m}^{3}$ - air density at the receiver inlet, $\mathrm{kg} / \mathrm{m}^{3}$;

$v_{\text {rec }}$ - air velocity in the receiver, $\mathrm{m} / \mathrm{s}$.

In the equipment in question, a receiving device of the

"Nozzle" type is selected, for which $\xi_{\text {rec }}=0.7$ [9].

The air velocity in the receiver is determined by the following formula [9]:

$$
v_{\text {rec }}=v \frac{F}{F_{\text {rec }}},
$$

where

$F$ and $F_{r e c}$ - cross-sectional area of the pipeline and the receiver pipe, $\mathrm{m}^{2}$. For approximate calculation it is allowed to take $F=F_{\text {rec }}$.

Then

$$
H_{r e c}=0.25 \rho_{r e c} \cdot v^{2}(1+\mu) .
$$

3) The amount of pressure drop to equalize the velocities of the material and air (acceleration of the material) and to retrieve (redress) the air-grain flow velocity after bending is determined by the following formula:

$$
\sum H_{o}=H_{o}+H_{o . b} .
$$

Pressure drop to equalize the velocities of the material and air (acceleration of the material) is determined by the following formula:

$$
H_{o}=i \cdot G \text {, }
$$

where

$G$ - conveyor capacity, $\mathrm{t} / \mathrm{h}$;

$i$ - pressure drop corresponding to the acceleration of 1 ton of material in the initial section of the pipeline [9, $10], \mathrm{Pa} /(\mathrm{t} / \mathrm{h})$, given by:

$$
i=\frac{M \cdot v}{D^{2}}
$$

where

$M=0.324$ - coefficient for coarse materials (soybean);

$v$ - air velocity, $\mathrm{m} / \mathrm{s}$;

$D$ - pipeline diameter, $\mathrm{m}$.

Ppressure drop to retrieve (redress) the air-grain flow velocity after bends is determined by the following formula:

$$
H_{o . b}=\sum_{j=1}^{n} H_{o . b . j}
$$

where

$n$ - number of bends.

The pressure drop after each bend $j$ is given by:

$$
H_{o . b . j}=\Delta y \cdot i \cdot G,
$$

where

$\Delta y$ - coefficient depending on the size of the central angle of the bend (Fig. 2), the ratio of the radius of the bend curvature to the diameter of the pipeline and the length of the straight section behind the bend.

Usually, a bend radius is adopted ten times pipeline diameter $(r=10 D)[6]$. In this case for elbow bend $(\alpha=$ $\left.90^{\circ}\right) \Delta y=0.4$ 
For the equipment in question whit two elbow bends (Fig. 1)

$$
H_{o . b}=2 \Delta y \cdot i \cdot G=0.8 i \cdot G
$$

4) The pressure drop from friction during the conveying of the air-grain flow in straight vertical $\left(H_{f r . v}\right)$ and horizontal $\left(H_{f r: h}\right)$ sections of the pipeline is determined by the following formulae

$$
\begin{aligned}
& H_{f r . v}=H_{c l}\left(1+K_{v} \cdot \mu\right), \\
& H_{f r . h}=H_{c l}\left(1+K_{h} \cdot \mu\right),
\end{aligned}
$$

where

$H_{c l}$ - pressure drop of clean air flow;

$K_{v}$ and $K_{h}$ - empirical coefficients.

Friction pressure drop of clean air flow is determined by the following formula:

$$
H_{c l}=H_{l, m} \cdot L,
$$

where

$H_{l . m \text {. }}$ - friction pressure drop (loss) of clean air flow per 1 $\mathrm{m}$ of pipeline, $\mathrm{Pa} / \mathrm{m}$;

$L$ - length of the straight sections of pipeline, $\mathrm{m}$.

The pressure drop $H_{l, m}$ is given by:

$$
H_{l, m}=\frac{\lambda}{D} \rho \frac{v^{2}}{2},
$$

where

$\lambda$ - empirical pipeline friction coefficient determined by Nikuradze's formula:

$$
\lambda=\frac{1}{\left(1.75+2 \lg \frac{D}{2 \delta}\right)^{2}},
$$

where

$\delta$ - pipe wall roughness, $\mathrm{m}$.

For usually used for grains (including soybean) pipes the wall roughness is accepted $\delta=0.2 \cdot 10^{-3} \mathrm{~m}$ [11].

The coefficient $K_{v}$ for soybean is given by:

$$
K_{v}=\frac{A_{v}(D-0.04)}{v^{1.33}}
$$

where

$A_{v}$ - coefficient, for grain $A_{v}=240$;

The coefficient $K_{h}$ for soybean is given by:

$$
K_{h}=\frac{A_{h} \cdot D}{v^{1.25}},
$$

where

$A_{h}$ - coefficient, for grain $\mathrm{A}_{\mathrm{h}}=150$;

5) The pressure drop in a bend (Fig. 2) $H_{b}$ is determined by the following formula:

$$
H_{b}=H_{b . c l}\left(1+K_{b} \cdot \mu\right),
$$

where

$H_{b . c l}$ - pressure drop (loss) of clean air flow in the bend; $K_{b}$ - bend loss factor given by:

$$
K_{b}=\frac{B^{\prime} \cdot D}{v^{1.25}\left(\frac{r}{D}\right)^{m}},
$$

where

$r$ - radius of curvature of center axis of the bend ( $r=$ $10 D$ in the equipment in question);

$B^{\prime}$ and $m$ - empirical coefficients. For air-grain flow [4]:

$B^{\prime}=620$ and $m=0.15$ for flow from horizontal to vertical direction

and

$B^{\prime}=550$ and $\mathrm{m}=0.23$ for flow from vertical to horizontal direction;

The pressure drop of clean air flow in the bend $H_{b . c l}$ is given by:

$$
H_{b . c l}=\Delta_{b} \cdot \xi_{b} \cdot \rho \frac{v^{2}}{2}
$$

where

$\Delta_{b}$ and $\xi_{b}$ - empirical coefficients from [4]:

$\Delta_{b}=1$ for elbow bend $\left(\alpha=90^{\circ}\right.$, Fig 2$)$;

$\xi_{\mathrm{b}}=0.36$ for pipe diameter $D=119 \ldots 125 \mathrm{~mm}$.

6) Pressure drop during vertical conveying is determined by the following formula:

$$
H_{v, c}=\rho \cdot g \cdot \mu \cdot S,
$$

where

$S$ - height of the vertical section $(S=10 \mathrm{~m}$ in the equipment in question).

$g$ - earth acceleration, $\mathrm{m} / \mathrm{s}^{2}$.

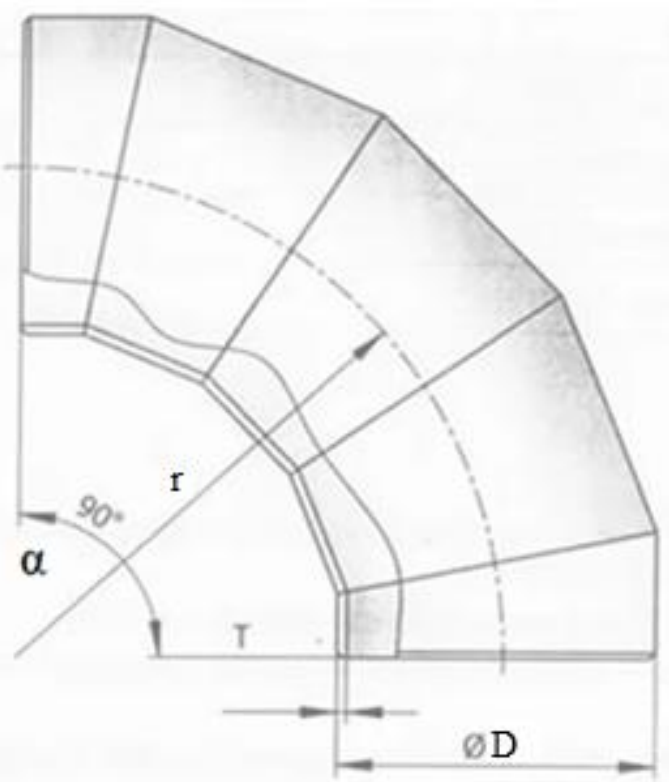

Fig. 2. Elbow bend of the pipeline for active ventilation (pos. 7 in Fig. 1) with $\alpha=90^{\circ}$ 
7) Pressure drop in a cyclone-unloader.

As unloading device a cyclone separator is chosen by the air-flow rate $Q_{c . u}$ and air velocity $v_{c . u}$ at its inlet nozzle. The needed cross-section area $F_{c . u}$ is given by $[12,13]$

$$
F_{c . u}=\frac{Q_{c . u}}{3600 v_{c . u}},
$$

where

$F_{c . u}$ - cross-section area of the inlet pipe of cycloneunloader, $\mathrm{m}^{2}$

$Q_{c . u}-$ volumetric flow rate of inlet air, $\mathrm{m}^{3} / \mathrm{h}$;

$v_{c . u}$ - velocity of inlet air, $\mathrm{m} / \mathrm{s}$.

When determining $Q_{c . u}$, a change in the air condition along the conveyor pipeline should be taken into account:

$$
Q_{c . u}=Q_{p c} \frac{\rho}{\rho_{c . u}}
$$

where

$\rho$ - air density at the inlet of the pipeline;

$\rho_{c . u}$ - air density at the inlet of the cyclone-unloader, which is given by:

$$
\rho_{c . u}=\frac{p_{a}-H_{p l}}{R_{s p} \cdot T},
$$

where

$p_{a}$-atmospheric pressure;

$H_{p l}$ - calculated pressure drop in the pipeline;

$R_{s p}$ - specific gas constant, for dry air $\mathrm{R}=288 \mathrm{~J} / \mathrm{kg} \cdot{ }^{\circ} \mathrm{K}$;

$T$ - absolute temperature at the end of the pipeline is equal to $\left(273+\mathrm{t}^{\circ} \mathrm{C}\right),{ }^{\circ} \mathrm{K}$.

Under normal atmospheric (free air) conditions $\left(p_{a}=\right.$ $101325 \mathrm{~Pa}, t^{\circ}=20^{\circ} \mathrm{C}$, and relative humidity $\varphi=50 \%$ ) $\rho=\rho_{a}=1.2 \mathrm{~kg} / \mathrm{m}^{3}$ and $T=273+20=293^{\circ} \mathrm{K}$.

Pressure drop in the pipeline $H_{p l}$ is calculated from formula (8) for a respective branch of the conveyor as follows:

$$
H_{p l}=\sum H_{o}+\sum H_{f r . v}+\sum H_{f r . h}+\sum H_{b}+H_{v, c}
$$

where

$\sum H_{o}$ - the amount of pressure drop to accelerate velocity of material fed into a pipeline to its conveying velocity (acceleration of the material) and to retrieve (redress) the air-grain flow velocity after bends (see formula (12));

$\sum H_{f r . v}, \sum H_{f r: h}$ - the amount of pressure drop from friction during the movement of the air-grain flow in the straight vertical and horizontal sections of the pipelines (see formulae (18) and (19));

$\sum H_{b}$ - the amount of pressure drop in the bends (see formula (25));

$H_{v, c}$ - pressure drop during the vertical conveying (see formula (28);

By choosing the inlet air velocity $v_{c . u}$, the required crosssection area $F_{c . u}$ is determined, and a cyclone type is selected. For the equipment in question $v_{c . u}=22.86 \mathrm{~m} / \mathrm{s}$ and $F_{c . u}=0.017 \mathrm{~m}^{2}$. Hence a cyclone type ЦР-400, with $F_{c . u}=0.018 \mathrm{~m}^{2}(D=400 \mathrm{~mm})$, from [3] is selected.

Pressure drop (loss) in the cyclone-unloader is determined by the following formula:

$$
H_{c . u}=\xi_{c . d} \cdot \rho_{c . u} \frac{v_{c . u}^{2}}{2},
$$

where

$\xi_{c . d}$ - loss factor, depended on the type of cyclone; $\rho_{c . u}$ - air density at the inlet of the cyclone-unloader, given by formula (31).

For the chosen cyclone (ЦР-400) $\xi_{c . d}=3.7$ and $\rho_{c . u}=1.1$ $\mathrm{kg} / \mathrm{m}^{3}$.

\subsection{Rotary valve calculation}

In the equipment in question, feeding devices are installed to seal the opening through which the material is fed to or unloaded from the conveyor [14]. In our case, (Fig. 1), that is, at the bottom of the container (lower nozzle 12). A rotary valve [4] ШУ-15 is selected. Mass flow rate of rotary valve $G_{r . v}$ (in $\mathrm{kg} / \mathrm{h}$ ) is determined as follows:

$$
G_{r, v}=0.06 V_{r, v} \cdot n \cdot \rho_{m} \cdot \beta_{r, v} \cdot \eta_{r, v},
$$

where

$V_{r, v}$ - displacement volume of the valve (per one revolution), $\mathrm{dm}^{3} / \mathrm{rev}$ (ШУ-15 is with $V_{l}=15 \mathrm{dm}^{3} / \mathrm{rev}$ );

$n$ - rotor's speed, rpm;

$\rho_{m}$ - material bulk density, $\mathrm{kg} / \mathrm{m}^{3}$;

$\beta_{r . v}$ - correction factor of bulk density, taking into account aeration, for grain materials equal to 0.7 [4];

$\eta_{r . v}$ - filling efficiency, for grain equal to 0.5 [4].

For soybean $\rho_{m}=720 \mathrm{~kg} / \mathrm{m}^{3}$ is accepted.

After following in formula (34)

$$
G_{r, v}=G,
$$

the rotor's speed can be obtained:

$$
n=\frac{G}{0.06 V_{r, v} \cdot \rho_{m} \cdot \beta_{r, v} \cdot \eta_{r, v}},
$$

The typical speed according to [6] is $20 \mathrm{rpm}$, which coincides with the producer's recommendation for $15 \div$ $30 \mathrm{rpm}$.

\subsection{Supply cyclone calculation}

A supply cyclone is selected according to the volume rate of air flow $Q_{s . c}$ entering the cyclone and the air velocity $v_{b . c}$ in its inlet. The required cross-sectional size of the inlet $F_{\text {s.c }}\left(\right.$ in $\left.\mathrm{m}^{2}\right)$ is determined as follows [13, 15]:

$$
F_{s . c}=\frac{Q_{s . c}}{3600 v_{s . c}},
$$

The air flow volumetric rate $Q_{s c}$ is determined as follows: 


$$
Q_{s . c}=\sum Q_{s . u}+\sum \Delta Q_{s . u} .
$$

After choosing the cyclone type, its pressure drop (loss) $H_{s . c}$ is determined by formula (9) as follows:

$$
H_{s . c}=\varphi_{s . c} \cdot \rho_{s . c} \frac{v_{s . c}^{2}}{2},
$$

where

$\varphi_{s . c}$ - loss factor, depended on the cyclone type; $v_{s . c}$ - air velocity in the cyclone inlet;

$\rho_{\text {b.c. }}$ - density of the air in the cyclone, determined by formula (31) as follows:

$$
\rho_{\text {s.c. }}=\frac{p_{a}-H_{p l}}{R_{s p} \cdot T}
$$

A cloth filter of the supply cyclone is selected according to the volumetric rate of air flow $Q_{s . c}$ entering the cyclone and the permissible load on the filter cloth. The required surface $F_{f}$ of the filter cloth is:

$$
F_{f}=\frac{Q_{f}}{60 q_{p e r}},
$$

where

$\mathrm{Q}_{\mathrm{f}}$ - air flow volume rate, $\mathrm{m}^{3} / \mathrm{h}$;

$q_{p e r}-$ permissible specific air load on filter cloth, $\mathrm{m}^{3} / \mathrm{min} \cdot \mathrm{m}^{2}$.

The air flow volumetric rate for one-stage filtration is determined as follows:

$$
Q_{f}=Q_{s . c}+\Delta Q_{s . c}
$$

where

$\Delta Q_{\text {s.c }}=36 \mathrm{~m}^{3} / \mathrm{h}[4]$ - the total amount of air leakage in the cyclone and connecting pipeline, $\mathrm{m}^{3} / \mathrm{h}$.

The pressure drop of a filter in case of grain conveying is determined as follows [4]:

$$
H_{f}=525 q^{1,3}
$$

For the conveyor in question a filter Г4-1БМФ-600 is chosen with following parameters [4]:

$Q_{f}=700 \mathrm{~m}^{3} / \mathrm{h} ; q_{p e r}=1.25 \mathrm{~m}^{3} / \mathrm{min} \cdot \mathrm{m}^{2} ; F_{f}=12 \mathrm{~m}^{2} ; H_{f}=$ $525 \mathrm{~Pa}$ for $q=1.0$.

\subsection{Blower calculation}

\subsubsection{Air-flow rate calculation}

The blower for the pneumatic conveyor is chosen according to the estimated air-flow rate $Q$ and the pressure $p_{u}$ according to the relevant characteristics. The estimated air-flow rate $Q$ is determined as follows [5]:

$$
Q=1.05\left(Q_{f}+\Delta Q_{f}\right),
$$

where
$Q_{f}$ - filter air flow rate, determined by formula (42), $\mathrm{m}^{3} / \mathrm{h}$ $\Delta Q_{f}$ - amount of air leakage in the filter, $\mathrm{m}^{3} / \mathrm{h}$. For chosen filter Г4-1БМФ-600 it is $\Delta Q_{f}=600 \mathrm{~m}^{3} / \mathrm{h}$;

The value of the selected rate must be on the downstream part of the characteristic curve $Q-p_{v}$ (i.e. to the right of the maximum pressure) and exceed the nominal by no more than $20 \mathrm{~m}^{3} / \mathrm{min}$ (at maximum efficiency) flow rate of the blower.

To choose a blower according to a characteristic made up for suction conditions under normal atmospheric conditions $\left(\rho=1.2 \mathrm{~kg} / \mathrm{m}^{3}\right)$, the pressure is determined by the formula:

$$
H_{b l}=H_{c a l} \frac{1.2}{\rho_{c a l}},
$$

where

$\rho_{\text {cal }}$ - calculated air density at the blower inlet determined as follows:

$$
\rho_{c a l}=\frac{p_{a}-H_{c a l}}{R T_{c a l}},
$$

where

$H_{c a l}$ - calculated required pressure in the conveyor, $\mathrm{Pa}$;

$T_{c a l}=\left(273+\mathrm{t}^{\circ} \mathrm{C}\right)-$ estimated absolute air temperature in summer for the area (in our case $\mathrm{t}=20^{\circ} \mathrm{K}$ ), $\mathrm{K}$;

$\rho_{a}-$ atmospheric pressure, $\mathrm{Pa}$.

The calculated required pressure in the conveyor is determined as follows:

$$
H_{c a l}=H_{p t}+H_{s . c}+H_{f}+H_{c o l l}+H_{\text {unac }}
$$

where

$H_{p t}$ - pressure drop in the conveyor, determined by formuls (8);

$H_{\text {s.c }}$ - pressure drop in the supply cyclone, determined by formula (39);

$H_{f}$ - pressure drop in the filter of the supply cyclone, determined by formula (43);

$\mathrm{H}_{\text {coll }}$ - pressure drop in the collector, considered [4] $1500 \mathrm{~Pa}$;

$\mathrm{H}_{\text {unac }}$ - unaccounted pressure drop, considered [4] -1000 $\mathrm{Pa}$.

\subsubsection{Motor power calculation}

The calculated power of the blower motor $P_{c a l}($ in $\mathrm{kW})$ is calculated as follows:

$$
P_{c a l}=\frac{Q \cdot H_{b l}}{3600 \cdot 1000 \eta_{b l} \cdot \eta_{t r} \cdot \eta_{\text {bear }}}
$$

where

$Q$ - estimated air-flow rate, determined by formula (44), $\mathrm{m}^{3} / \mathrm{h}$;

$H_{b l}$ - required pressure, determined by formula (45), $\mathrm{Pa}$

$\eta_{b l}$ - blower efficiency, taken from the aerodynamic characteristics of the machine;

$\eta_{t r}$ - transmission efficiency, equal to 1.0 when the blower is on the shaft of the motor, equal to 0.98 if there 
is a coupling, and equal to 0.95 in case of a belt transmission;

$\eta_{\text {bear }}=0.99-$ bearing efficiemcy.

After the abovementioned calculations the blower is chosen.

For the conveyor in question $Q=1380 \mathrm{~m}^{3} / \mathrm{h}$.

Transmission efficiency is considered $\eta_{\mathrm{tr}}=0.95$;

According calculation the blower can be selected.

\subsection{Nozzle choice}

Nozzles with filters (pos. 15 and 16 in Fig. 1) for the removal of air flow from the cyclones-unloaders are chosen by the air flow rate $Q_{c . d s}$ which depends on the volume flow rate $Q_{c . u}$, of the cyclone inlet air flow (see formula 30). It may be considered

$$
Q_{c . d s}=Q_{c . u}+\Delta Q_{c . d s},
$$

where

$\Delta Q_{c . d s}=(3 \ldots 6) \%$ of $Q_{c . u}$

For the equipment in question $\Delta Q_{c . d s}=0.05 Q_{c . u}$ is chosen.

\section{Analysis of the results}

On the basis of the developed methodology, the calculation of the studied equipment (Fig1) was made with the following input data:

- Average daily mass flow rate

- Operating time

$40 \mathrm{t} /$ day

- Specified (real) mass flow rate $G_{s p} \quad 4 \mathrm{t} / \mathrm{h}$

- Pipeline length $L$

- Height of the vertical section $S$

$34 \mathrm{~m}$

$10 \mathrm{~m}$

- Number of bends

2 by $90^{\circ}$

- Solids loading ratio of the grain-air flow $\mu \quad 3.6 \mathrm{~kg} / \mathrm{kg}$

- Particles (soybean) velocity $v_{\text {spe }}$

$15 \mathrm{~m} / \mathrm{s}$

After calculations following results are obtained:

- Estimated (ideal) mass flow rate $G$

$4.8 \mathrm{t} / \mathrm{h}$

- Estimated air velocity $v$

- diameter of pipeline bore $D$

$22.86 \mathrm{~m} / \mathrm{s}$

- Pressure drop in the receiver $H_{\text {rec }}$

$125 \mathrm{~mm}$

$31.54 \mathrm{~Pa}$

- Amount of pressure drop of material acceleration after

feeder and bends $\sum H_{o}$

$3189 \mathrm{~Pa}$

- Pressure drop (loss) of friction in vertical sections $\sum H_{f r . v}$ horizontal sections $\sum H_{f r . h}$

- Pressure drop in bends $\sum H_{b}$

$1147 \mathrm{~Pa}$

$1735 \mathrm{~Pa}$

$989 \mathrm{~Pa}$

- Pressure drop of vertical conveying $H_{v . c}$

- Air-flow rate at cyclone-unloader inlet $C_{r u}$

- Air velocity in cyclone-unloader inlet $v_{c . u}$

43.2 $\mathrm{Pa}$

$0.2 \mathrm{~m}^{3} / \mathrm{h}$

- Air density at cyclone-unloader inlet $\rho_{c . u}$

- Pressure drop in pipeline $H_{p l}$

$22.86 \mathrm{~m} / \mathrm{s}$

$1,11 \mathrm{~kg} / \mathrm{m}^{3}$

2914,23 $\mathrm{Pa}$

$720 \mathrm{~m}^{3} / \mathrm{h}$

- air-flow rate at cyclone-unloader inlet $Q_{c . u}$

- Required cross-section area $F_{c . u}$

$0.017 \mathrm{~m}^{2}$

- Type of selected cyclone-unloader with $D=400 \mathrm{~mm}, F_{c . u}=0.018 \mathrm{~m}^{2}$
- Pressure drop in cyclone-unloader $H_{c . u}$

$1063 \mathrm{~Pa}$

- Mass flow rate of rotary valve $G_{r . v}$ $4800 \mathrm{~kg} / \mathrm{h}$

- Required cross-section area of

supply cyclone $F_{c . u}$

$0.0091 \mathrm{~m}^{2}$

$1450 \mathrm{~Pa}$

- Pressure drop in supply cyclone $H_{s . c}$

- Required surface of filter cloth $F_{f}$

- Type of selected filter

$12 \mathrm{~m}^{2}$

- Pressure drop of supply cyclone filter $H_{f}$

- Estimated air-flow rate $Q$

$525 \mathrm{~Pa}$

- Required pressure in the conveyor $H_{c a l}$

$1423 \mathrm{~m}^{3} / \mathrm{h}$

- Calculated air density at blower inlet $\rho_{c a l}$

$15706 \mathrm{~Pa}$

- Required power of the blower $P_{c a l}$

$1.01 \mathrm{\kappa g} / \mathrm{m}^{3}$

$8.4 \mathrm{~kW}$

- Type of selected blower TB-65-1,2 [14]

- Air-flow rate in cyclone-unloader outlet nozzle

$22.86 \mathrm{~m} / \mathrm{s}$

- Type of selected nozzle "Soplo" (Сопло)

The proposed methodology makes it possible to choose the main parameters and modes of operation of the pneumatic conveyor for soybeans and on this basis to choose the optimal pneumatic conveying aggregate for the proposed modular equipment for soybeans storage with active ventilation.

The proposed methodology allowed to establish that, the optimal bore of the pipeline should be no more than $125 \mathrm{~mm}$, as a result of which the power consumption of the electric drive is reduced by $3-5 \%$. Accordingly, the total cost of equipment is reduced.

\section{Conclusion}

An innovative way for soybean storage with active ventilation is proposed.

A methodology for studying the productivity (capacity) and power consumption of a pneumatic conveyor of soybeans is proposed. The influencing factors are considered. Their variation allows for the choice of a conveying aggregate with optimal parameters.

The methodology is applied (as an example) for the calculation of pneumatic conveying equipment for container-modular storage with active ventilation of soybeans in farms.

\section{References}

1. On approval of the rules for storage of grain. Decree of the Minister of Agriculture of the Republic of Kazakhstan, No. 4-1/573 from June 26, 2015.

2. A.K. Atykhanov, D.P. Karaivanov, S.T. Duisenova. Equipment for storage of grain material with active ventilation. Patent KZ U 3135 A01F 25/00, (24.09.2018)

3. N.P. Volodin, M.G. Kastornykh, A.I. Krivoshein, Handbook of aspiration and pneumatic conveying equipment, Moscow: Kolos, (1984)

4. F.G. Zuev, Handbook of transport and handling machines, Moscow: Kolos, (1983) 
5. A.Y. Malis, M.G. Kastornykh, Pneumatic transport for bulk materials, Moscow: Agropromizdat, (1985)

6. D. Mills, Pneumatic conveying design guide, Second edition. Oxford: Elsevier ButterworthHeinemann, (2004) ISBN 0-7506-5471-6

7. A.Y. Malis, Pneumatic transport for bulk materials, Moscow: Kolos, (1969)

8. M. Lech, Powder Technology, 114, 1-3 (2001)

9. E.V. Manjula, P.J. Hiromi, W.K. Ariyaratne, R. Chandana, M.C. Melaaen. Powder Technology, 305 (2017)

10. P.W. Wypych, Pneumatic conveying of bulk solids. Dissertation. Department of Mechanical Engineering, University of Wollongong [Australia] (1989) http://ro.uow.edu.au/theses/1590.
11. A.G. Kasatkin, General chemical technology of organic substances, Moscow (1966)

12. F.P. Maron, A.V. Kuzmin, Handbook of handling machines mechanisms calculations, Minsk: Vysshaya shkola (1977)

13. A.O. Spivakovskiy, V.K. Kyachko, Handling machines, Moscow, Mashinostroenie (1990)

14. P. Chand, D.P. Ghosh, Journal of Agricultural Engineering Research, 13, 1 (1968)

15. R.B. Hevko, B.O. Yazlyuk, M.V. Liubin, O.A. Tokarchuk, O.M. Klendii, V.R. Pankiv, INMATEH: Agricultural Engineering (Bucharest, Romania), 51, 1 (2017)

16. Catalogue. JSC "Bryansk repair and mechanical plant". http://www.brmzavod.ru/ 